\title{
REUSE OF TEXTILE WASTEWATER AFTER HOMOGENIZATION-DECANTATION TREATMENT COUPLED TO PVDF ULTRAFILTRATION MEMBRANES
}

\author{
V. Buscio (1), M.J. Marín (2), M. Crespi (1), C. Gutiérrez-Bouzán (1)*
}

(1) Institut d'Investigació Tèxtil i Cooperació Industrial de Terrassa (INTEXTER), Universitat Politècnica de Catalunya-BarcelonaTech (UPC). Carrer Colom 15, 08222, Terrassa, Spain.

(2) Vincolor S.A., Carrer del Llobregat 25, 08223 Terrassa, Spain

Corresponding author: Tel.: +34 9373980 08; fax: +34 937398272 .

E-mail addresses: gutierrez@intexter.upc.edu

\section{Abstract}

The textile industry is one of the largest consumers of water in the world and its wastewater is a serious problem when it is discharged without the proper treatment. In this work, wastewater generated by textile industry was treated coupling a homogenization-decantation treatment with polyvinylidene difluoride (PVDF) ultrafiltration membranes.

Initially, the wastewater was aerated in a homogenization-decantation tank where $17 \%$ colour and $10 \%$ chemical oxygen demand (COD) were removed. The aerated effluent was treated with an ultrafiltration membrane in order to reuse the permeate in new dyeing processes. Firstly, the ultrafiltration treatment was performed in a laboratory plant. The permeate analysis showed $20 \%$ colour removal and $60 \%$ COD decrease. On the basis of these results, a semi-industrial system was built. With this plant, the permeate characterization showed similar results. The system was found to be scalable and suitable for the treatment of this kind of effluents.

Finally, new dyeings were performed with both permeates. Monochromatic dyeings were carried out with $100 \%$ permeate whereas $50 \%$ permeate was reused for dyeings 
with a mixture of three dyes. The colour differences were found to be lower than 1.5 , which was the acceptance value established.

Keywords: real textile wastewater; permeate reuse; ultrafiltration; dyeing process; membranes

\section{Introduction}

The textile industry is characterized by high water consumption. Up to $100 \mathrm{~L}$ of water are required to produce a kilogram of textile product [1]. Wastewater from textile industry contains different kind of dyes and chemical additives $[2,3]$, which cannot be easily degraded.

The most applied wastewater treatments are based on biological or physical-chemical processes. In general, conventional biological treatment provides good chemical oxygen demand (COD) removal, but low efficiencies in discoloration due to the chemical stability and resistance to microbiological attack of the dyes [4,5]. Chemical coagulation can remove the colour completely, but it generates a sludge which requires an additional treatment to be destroyed $[6,7]$. These methods are able to meet legislative requirements but they do not allow water reuse in textile processes [8]. Advanced oxidation treatments such as photo-fenton [9], photocatalytic [10] and electrochemical [11] have been studied in order to improve the efficiency in colour removal. Good results were obtained although they were found to be quite expensive [2]. Membrane technology is nowadays an attractive alternative to treat textile wastewater. In general, nanofiltration [12-14] and reverse osmosis [15] membranes have been studied to treat textile effluents. Its main advantage is that they can be applied to remove many kind of dyes, producing a concentrate, where dyes are retained, and a permeate free of dyes. Some studies have be focussed on the reuse of dyes concentrate [16] but the reuse of permeate in new processes is more advantageous. 
Direct feed to membrane modules can produce irreversible fouling. As a result, the maintenance cost of the membrane is increased and its life time is reduced [17]. If advanced treatments like membrane technologies are combined with conventional processes, the quality of the effluent treated is good enough to be reused [18] and the fouling observed decreases. Generally, the combination of membranes process with coagulation-flocculation [19-22] and biological treatments $[2,3,23]$ have been studied. The reuse of textile wastewater is an important challenge, specially the effluents from polyester dyeing. In fact, the liquor ratio (amount of fibre/water) for conventional dyeing of polyester fabrics is generally $1: 10-1: 20$, that implies the use of $10-20$ ton water for each ton fabric. In addition, the consumption of polyester fibre has increased dramatically in the lasts years. Nowadays this fibre represents about the $50 \%$ of the total world textile fibre consumption and it still has an increasing demand [24]. Taking into account these considerations, this work is focused on the treatment and reuse of wastewater generated by a textile mill specialized in polyester dyeing. The wastewater was treated by coupling a homogenization-decantation treatment with two polyvinylidene difluoride (PVDF) ultrafiltration membranes. The permeate was reused in new polyester dyeings. Finally, fabrics dyed with the reused water were evaluated respect to references carried out with softened tap water.

Several authors have published studies about treatment of textile effluents by membranes technologies. In these studies, after exhaustive analyses of the treated effluents, they conclude the suitability of permeate to be reused. But, to the best of our knowledge, a complete study of permeate reuse in new dyeings, both at laboratory and industrial scale, has not been yet carried out for any of them.

\section{Experimental}

\subsection{Reagents}

Nine Foron disperse dyes provided by Archroma-Spain were selected for the study of permeate reuse: Blue RD-S (referred as FB), Brilliant Red S-RGL 200 (FR), Brilliant 
Yellow RD-E 0.5 (FY), Marine Blue S-2GRL 200 (FM), Rubine RD-GFL 200 (FRU), Scarlet RD-S 0.5 (FS), Black BLN 200 (FBL), Yellow-Brown S-2RFL 150 (FYB) and Blue E-BL 150 (FB150). Figure 1 shows the available structures of the dyes FYB, FRU, FB150, and FR. The structures of the other dyes have not been already published.

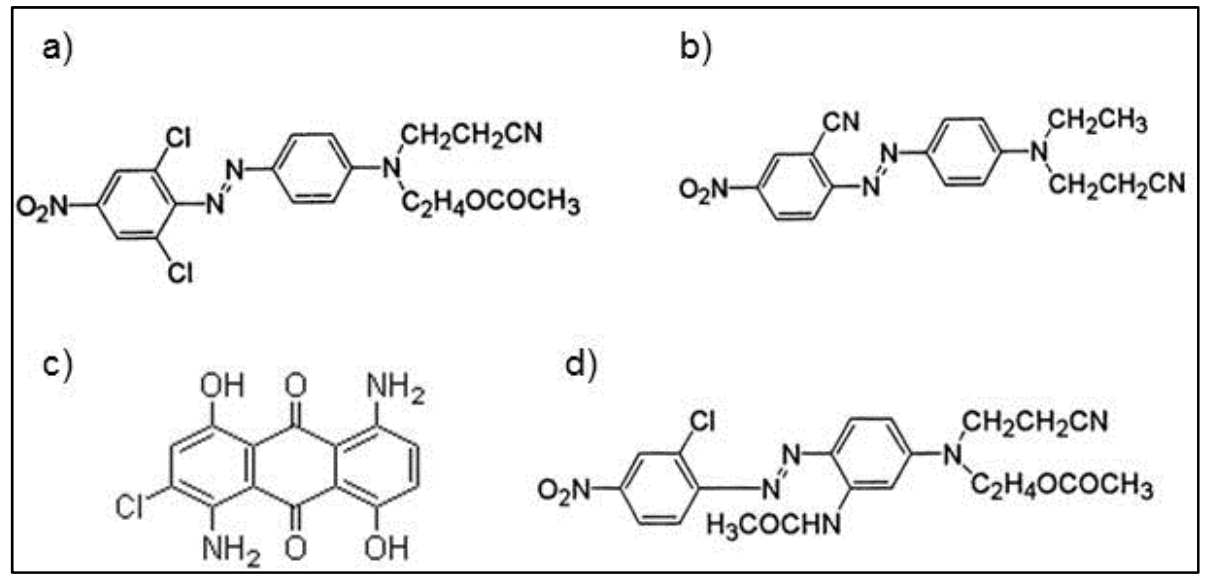

Figure 1- Chemical structure of a) Yellow-Brown S-2RFL 150 (FYB), b) Rubine RD-GFL 200 (FRU), c) Blue E-BL 150 (FB150), d) Brilliant Red S-RGL 200 (FR).

Sodium hypochlorite solution (6-14\% active chlorine) acquired from Sigma-Aldrich was used for the membrane cleaning.

\subsection{Wastewater}

The textile effluents were supplied for the mill Vincolor (Terrassa, Spain). The effluents were collected after the dyeing processes during different days.

The dyeing process takes place in different steps as it is shown in Figure 2.

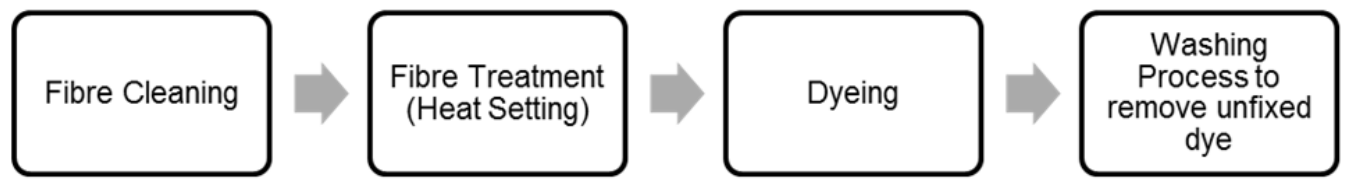

Figure 2- Schema of the dyeing process

The main characteristics of the wastewater which was discharged into the homogenization-decantation treatment are presented in Table 1. 
Table 1- Characteristics of wastewater discharged into the homogenization-decantation treatment

\begin{tabular}{cc}
\hline Parameter & Feed \\
\hline $\mathrm{pH}$ & 6.9 \\
$\mathrm{COD}\left(\mathrm{mg} \cdot \mathrm{L}^{-1}\right)$ & 806 \\
Conductivity $\left(\mu \mathrm{S} \cdot \mathrm{cm}^{-1}\right)$ & 1825 \\
Alkalinity $\left({ }^{\circ} \mathrm{F}\right)$ & 15 \\
Colour $\left(\mathrm{mg} \mathrm{Pt}-\mathrm{Co} \cdot \mathrm{L}^{-1}\right)$ & 300 \\
$\mathrm{SS}\left(\mathrm{mg} \cdot \mathrm{L}^{-1}\right)$ & 112 \\
Hardness $\left({ }^{\circ} \mathrm{F}\right)$ & 5 \\
$\mathrm{Cl}-\left(\mathrm{mg} \cdot \mathrm{L}^{-1}\right)$ & 270 \\
$\mathrm{SO} 42-\left(\mathrm{mg} \cdot \mathrm{L}^{-1}\right)$ & 387 \\
\hline
\end{tabular}

\subsection{Homogenization-decantation treatment}

The treatment was carried out in a homogenization tank $\left(V=200 \mathrm{~m}^{3}\right)$, where the wastewater generated in the different steps of the dyeing process, was discharged. The Hydraulic Retention Time (HRT) was 2.5 days. A screening process was applied to the effluents before the homogenization treatment in order to remove residual fibres. A cylindro-conical clarifier $\left(\mathrm{V}=18 \mathrm{~m}^{3}\right)$ was placed after the treatment.

\subsection{Ultrafiltration modules}

In this study, two hollow fibre membranes modules were studied: UOF-1b (Motimo Membrane Technology, China) and UOF-4 (Motimo Membrane Technology, China), referred herein after as $U-1 b$ and $U-4$, respectively. In Table 2 are described the main characteristics of these membranes. 
Table 2- Membrane characteristics

\begin{tabular}{ccc}
\hline Membrane & Pore size $(\mu \mathrm{m})$ & Membrane Surface $\left(\mathrm{m}^{2}\right)$ \\
\hline $\mathrm{U}-1 \mathrm{~b}$ & 0.04 & 0.5 \\
$\mathrm{U}-4$ & 0.03 & 40 \\
\hline
\end{tabular}

Two pilot plants were built to accommodate the membrane modules, according to the geometry and specifications of each membrane.

The pilot 1 (Figure 3) was equipped with $U-1 b$ membrane. It was fed by a $100 \mathrm{~L}$ tank. Peristaltic pumps were used for feed, permeate, and concentrate effluents. The pilot operated in cycles of 15 minutes of filtration and 30 seconds of backwashing with permeate.

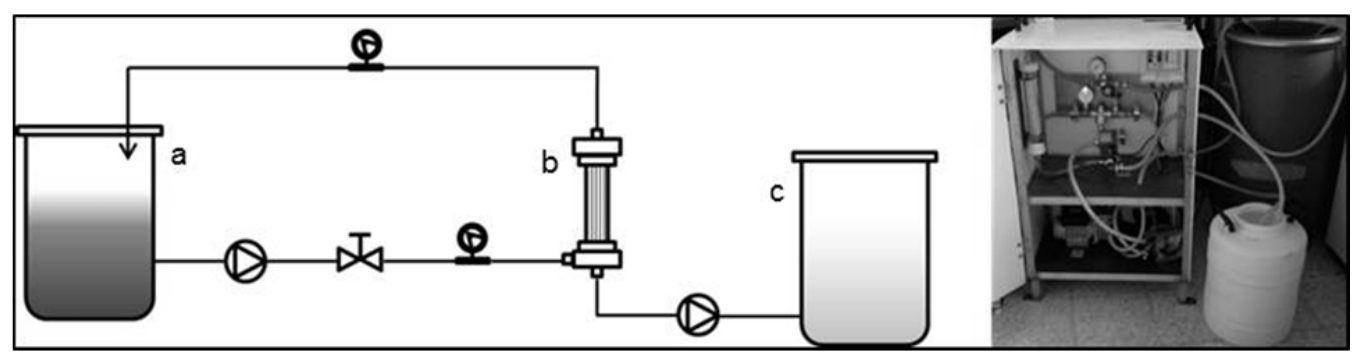

Figure 3- Pilot 1 with U-1b membrane. a) Feed tank, b) U-1b Membrane, c) Permeate tank

The pilot 2 (Figure 4) was a semi-industrial system with U-4 membrane. Before the membrane module, two meshes (500 and $200 \mu \mathrm{m}$ ) were placed to remove the high particle size. The volume of feeding tank was $1000 \mathrm{~L}$. The membrane worked in cycles of 30 minutes of filtration and 30 seconds of backwashing with permeate.

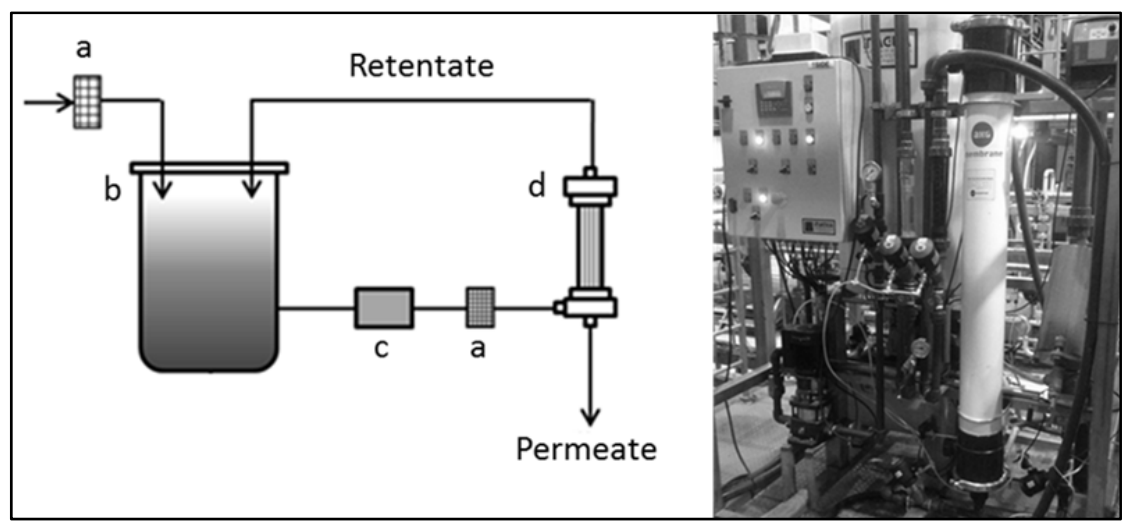

Figure 4- Semi-industrial system. a) Meshes, b) Feed tank, c) Control system, d) U-4 membrane 
Finally, after each filtration process, the membranes were cleaned with a sodium hypochlorite solution $\left(5 \mathrm{mg} \cdot \mathrm{L}^{-1}\right)$.

\subsection{Analytical methods and measurements}

The permeate flux was determined to evaluate the membrane fouling. It was determined by measuring the permeate volume collected in a certain period and using the following equation:

$J\left(L \cdot m^{-2} \cdot h^{-1}\right)=V / A \cdot \Delta t$

Where $\mathrm{J}$ is the permeate flux $\left(\mathrm{L} \cdot \mathrm{m}^{-2} \cdot \mathrm{h}^{-1}\right), A$ is the effective area of the membrane $\left(\mathrm{m}^{2}\right)$ and $\mathrm{V}$ is the collected volume in a time interval $\Delta t\left(L \cdot h^{-1}\right)$.

COD was determined according to the method $5220 \mathrm{C}$ recommended by American Public Health Association [25]. The COD reduction was calculated using the following equation:

$\operatorname{RCOD}=\left(\left(\mathrm{COD}_{\mathrm{f}}-\mathrm{COD}_{\mathrm{p}}\right) / \mathrm{COD}_{\mathrm{f}}\right) \cdot 100$

where $C O D_{f}$ and $C O D_{p}$ are the COD values in feed and permeate respectively. The conductivity was measured following the method 2510 B [25] with a Conductimeter GLP 31 (CRISON). The $\mathrm{pH}$ was determined according to the method $4500 \mathrm{H}^{+} \mathrm{B}$ [25] using a pHmeter GLP 21 (CRISON).

Suspended solids (SS), alkalinity and colour measurements were performed following standard methods (methods 2540D, 2320B and 2120B respectively) [25].

Water hardness was measured by complexometric titration with a standard solution of ethylenediamminetetraacetic acid (method 2340C) [25].

Finally, the determination of anions chloride $\left(\mathrm{Cl}^{-}\right)$and sulphate $\left(\mathrm{SO}_{4}{ }^{2-}\right)$ were carried out with Ion Chromatography ISC-1000 (Dionex) (method 4110B) [25].

\subsection{Permeate reuse}


The reuse dyeing tests were performed in a laboratory dyeing machine (Testherm 90-

S) according to the mill procedure: $10 \mathrm{~g}$ of polyester fabric, dye concentration $0.5 \%$

o.w.f (over weight of fibre) and liquor ratio 1:15 (1 g fibre/15 $\mathrm{mL}$ dye bath).

Dyeings with only one dye (monochromies) were carried out with $100 \%$ permeate. For dyeings with a mixture of three dyes (trichromies), only $50 \%$ permeate was reused due to the different behaviour of each dye. Dyed fabrics were evaluated with respect to the corresponding reference (performed with softened tap water). The experiments were run in duplicate.

\subsection{Dyed fabric evaluation}

The quality of dyed fabrics was studied from colour differences $\left(\mathrm{DE}_{\mathrm{CMC}}(\mathrm{l}: \mathrm{C})\right)$ using a MINOLTA CM 3600d spectrophotometer. The difference in colour was determined in conformity with the Standard UNE-EN ISO 105-J03 [26].

The equation for $\mathrm{DE}_{\mathrm{CMC}}(\mathrm{l}: \mathrm{c})$ describes an ellipsoidal volume with axes in the direction of lightness $(L)$, chroma $(C)$, and hue $(H)$ centered about a standard. Colour difference is composed of three components:

- Lightness component $\left(\mathrm{DL}_{\mathrm{CMC}}\right)$ that is weighted by the lightness tolerance $\left(D L^{*} / I S_{L}\right)$. If $D L_{C M C}$ is positive, the reused dyeing is lighter than the standard. If $\mathrm{DL}_{\mathrm{CMC}}$ is negative, the reused dyeing is darker than the standard.

- Chroma component $\left(\mathrm{DC}_{\mathrm{CMC}}\right)$ that is weighted by the chroma tolerance $\left(D C^{*}{ }_{a b} / \mathrm{CS}_{\mathrm{c}}\right)$. If $\mathrm{DC}_{\mathrm{CMC}}$ is positive, the reused dyeing is more chromatic than the standard. If $\mathrm{DL}_{\mathrm{CMC}}$ is negative the reused dyeing is less chromatic than the standard.

- Hue component $\left(\mathrm{DH}_{\mathrm{CMC}}\right)$ that is weighted by the hue tolerance $\left(\mathrm{DH}^{*}{ }_{\mathrm{ab}} / \mathrm{S}_{\mathrm{H}}\right)$. It describes the difference between the hue angle of the standard and the hue angle of the reused dyeing in a polar coordinate.

Colour difference is calculated from the following equation:

$\mathrm{DE}_{\mathrm{CMC}}(\mathrm{I}: \mathrm{c})=\left[\left(\mathrm{DL}^{*} / \mathrm{IS} \mathrm{L}^{2}+\left(\mathrm{DC}^{*}{ }_{\mathrm{ab}} / \mathrm{CS}_{\mathrm{C}}\right)^{2}+\left(\mathrm{DH}^{*}{ }_{\mathrm{ab}} / \mathrm{S}_{\mathrm{H}}\right)^{2}\right]^{1 / 2}\right.$ 
The lengths of the semi axes of the ellipsoid are calculated from the values $L^{*}{ }_{r}, C^{*}{ }_{a b, R}$ and $h_{a b, R}$, that correspond to the reference as follows:

$S_{L}=0.040975 L^{*}{ }_{R} /\left(1+0.01765 L^{*}\right)$ if $L^{*}{ }_{R} \geq 16$ or $S_{L}=0.511$ if $L^{*}{ }_{R}<16$

$S_{C}=\left[0.0638 C^{*}{ }_{a b, R} /\left(1+0.0131 C^{*}{ }_{a b, R}\right)\right]+0.638$

$S_{H}=(F T+1-F) S_{c}$

where

$F=\left(\left(C^{*}{ }_{a b, R}\right)^{4} /\left(\left(C^{*}{ }_{a b, R}\right)^{4}+1900\right)\right)^{1 / 2}$

$T=0.36+\left|0.4 \cos \left(35+h_{a b, R}\right)\right|$ if $h_{a b, R} \geq 345^{\circ}$ or $h_{a b, R} \leq 164^{\circ}$

or $T=0.56+10.2 \cos \left(168+h_{a b, R}\right) \mid$ if $164^{\circ}<h_{a b, R}<345^{\circ}$

In summary, a dyeing is considered acceptable when the $D E_{C M C}(l: c)$ value is lower than 1.5, measured by MINOLTA CM 3600d spectrophotometer with respect to a reference sample.

3. Results and discussion

3.1 Homogenization-decantation treatment

Textile wastewater shows high variability and its main characteristics depend mainly on the dyeing process and on the type of fibre. Therefore, the homogenization-decantation treatment was applied to improve the membrane process as the membrane was exposed to a more homogenous feed.

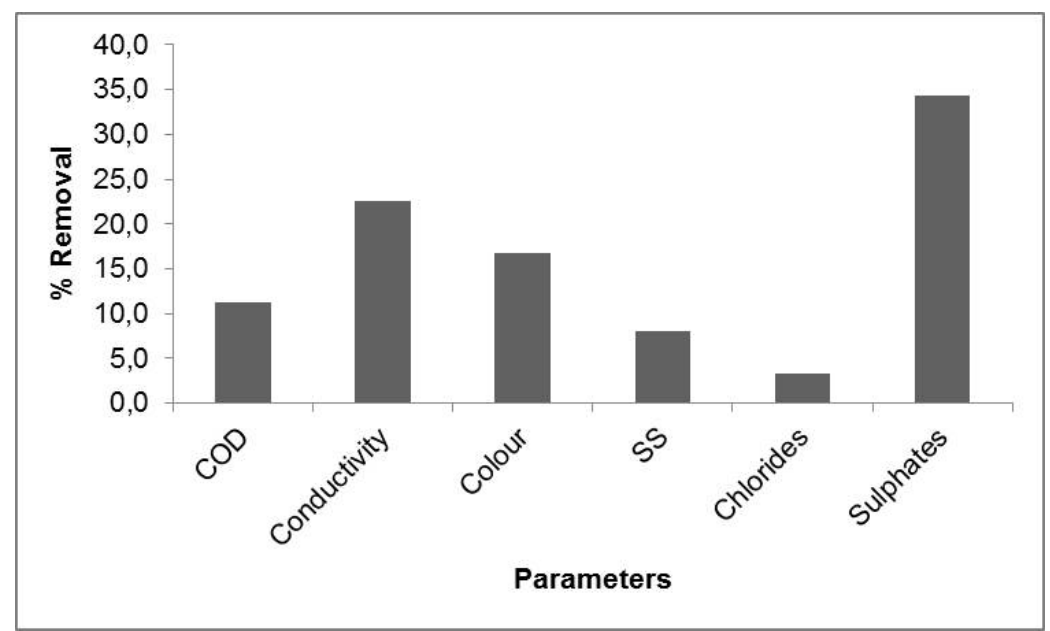

Figure 5- \%Removal in the homogenization-decantation treatment 
As can be seen in Figure 5, after the homogenization-decantation treatment, COD and colour removal were $10 \%$ and $17 \%$ respectively. This reduction is mainly due to the mixing of the different effluents, causing a dilution of the different compounds present in the wastewater. The $\mathrm{Cl}^{-}$concentration remained almost constant and the $\mathrm{SO}_{4}{ }^{2-}$ removal was $34 \%$, which provided $23 \%$ conductivity reduction. This phenomenon could be attributed to the precipitation of sulphate and calcium ions present in the effluent producing the salt. The alkalinity and hardness values were also lower after the treatment.

The clarifier reduced $8 \%$ suspended solids. The low efficiency of the clarification process can be attributed to the effect of surfactants in the effluent, which are used as auxiliary agents for dyeing and washing processes.

The homogeneous effluent was finally treated with $U-1 b$ membrane.

\subsection{Membrane treatment}

\subsubsection{Pilot 1 with U-1b membrane}

After homogenization-decantation treatment, three effluents (referred as E1, E2 and E3) were treated by means of an ultrafiltration membrane lab pilot. The transmembrane pressure was set at 0.2 bar. The permeate flux remained constant at 10 $\mathrm{L} \cdot \mathrm{m}^{-2} \cdot \mathrm{h}^{-1}$ during the experiment (90 minutes). The membrane fouling has been reported as a major problem to the further application of UF technology in wastewater treatment [27], because it produces a reduction in the permeability and consequently the maintenance cost of the membrane is increased and its life time is reduced [17]. The membrane material is an important factor in the membrane fouling. In general, polymers such as PVDF, polysulfone (PS), polyacrylonitrile (PAN) and cellulose triacetate $(\mathrm{CA})$ are employed to design membranes. The material provides different characteristics to the membranes: pore size, porosity and hydrophobicity $[28,29]$. Although PVDF membranes have hydrophobic characteristics [30] and therefore they have a certain tendency of fouling, they have been widely used due to their thermal 
stability and resistance to corrosion from many chemicals and organic compounds [30,31]. In addition, PVDF ultrafiltration membranes have shown percentage of dye retention and COD removal up to $90 \%$ when they are applied to treat textile wastewater [32]. In this study, the low fouling observed with this pilot showed the feasibility of applying PVDF membranes to treat textile wastewater.

The efficiency of the membrane process was determined with the permeate characterization (referred as P1, P2 and P3). Their main characteristics and the efficiency of the process are shown in Table 3.

Table 3- Effluents characterization and efficiency in the treatment with U-1b membrane

\begin{tabular}{lccccccccc}
\hline \multicolumn{1}{c}{ Parameter } & $\mathrm{E} 1$ & $\mathrm{P} 1$ & $\%$ & $\mathrm{E} 2$ & $\mathrm{P} 2$ & $\%$ & $\mathrm{E} 3$ & $\mathrm{P} 3$ & $\%$ \\
\hline $\mathrm{pH}$ & 7.5 & 7.9 & - & 7.6 & 7.6 & - & 7.4 & 7.5 & - \\
$\mathrm{COD}\left(\mathrm{mg} \cdot \mathrm{L}^{-1}\right)$ & 732 & 237 & 67.6 & 553 & 319 & 42.3 & 864 & 275 & 68.2 \\
Conductivity & 1426 & 1378 & 3.4 & 1383 & 1404 & - & 1429 & 1475 & - \\
$\left(\mu \mathrm{S} \cdot \mathrm{cm}^{-1}\right)$ & & & & & & & & & \\
Alkalinity $\left({ }^{\circ} \mathrm{F}\right)$ & 14 & 14 & - & 14 & 14 & - & 14 & 14 & 0.0 \\
Colour $(\mathrm{mg} \mathrm{Pt}-$ & 250 & 200 & 20.0 & 300 & 250 & 16.7 & 300 & 200 & 33.3 \\
Co $\left.\cdot \mathrm{L}^{-1}\right)$ & & & & & & & & & \\
$\mathrm{SS}\left(\mathrm{mg} \cdot \mathrm{L}^{-1}\right)$ & 161 & 2 & 98.8 & 44 & 2 & 95.5 & 309 & 2 & 99.4 \\
${\mathrm{Hardness}\left({ }^{\circ} \mathrm{F}\right)}^{2}$ & 2 & 2 & - & 2 & 2 & - & 2 & 2 & - \\
$\mathrm{Cl}^{-}\left(\mathrm{mg} \cdot \mathrm{L}^{-1}\right)$ & 254 & 249 & 2.0 & 291 & 284 & 2.4 & 256 & 242 & 5.5 \\
$\mathrm{SO}_{4}{ }^{2-}\left(\mathrm{mg} \cdot \mathrm{L}^{-1}\right)$ & 250 & 237 & 5.2 & 276 & 259 & 6.2 & 244 & 236 & 3.3 \\
\hline
\end{tabular}

From Table 3 it can be concluded that about $60 \%$ COD decrease and $20 \%$ colour removal were achieved. During the dyeing process different auxiliary products are employed. For example, a mixture of organic acids is added as a buffer, to maintain the $\mathrm{pH}$ constant. The membrane can retain these products resulting in a reduction of $\mathrm{COD}$ and also in an increase of $\mathrm{pH}$. Also, suspended solids were completely removed with 
the membrane treatment. The $\mathrm{Cl}^{-}$and $\mathrm{SO}_{4}{ }^{2-}$ removals were about $3 \%$ and $5 \%$ respectively. It is important to highlight that the UF membranes cannot retain ions.

Finally, conductivity, hardness, alkalinity did not change with respect to the initial effluents.

According to results of section 3.1 and 3.2 .1 , the combination of homogenizationdecantation and PVDF ultrafiltration was suitable to treat textile wastewater as it reduced all the studied parameters, except the $\mathrm{pH}$ which remained practically constant (Figure 6).

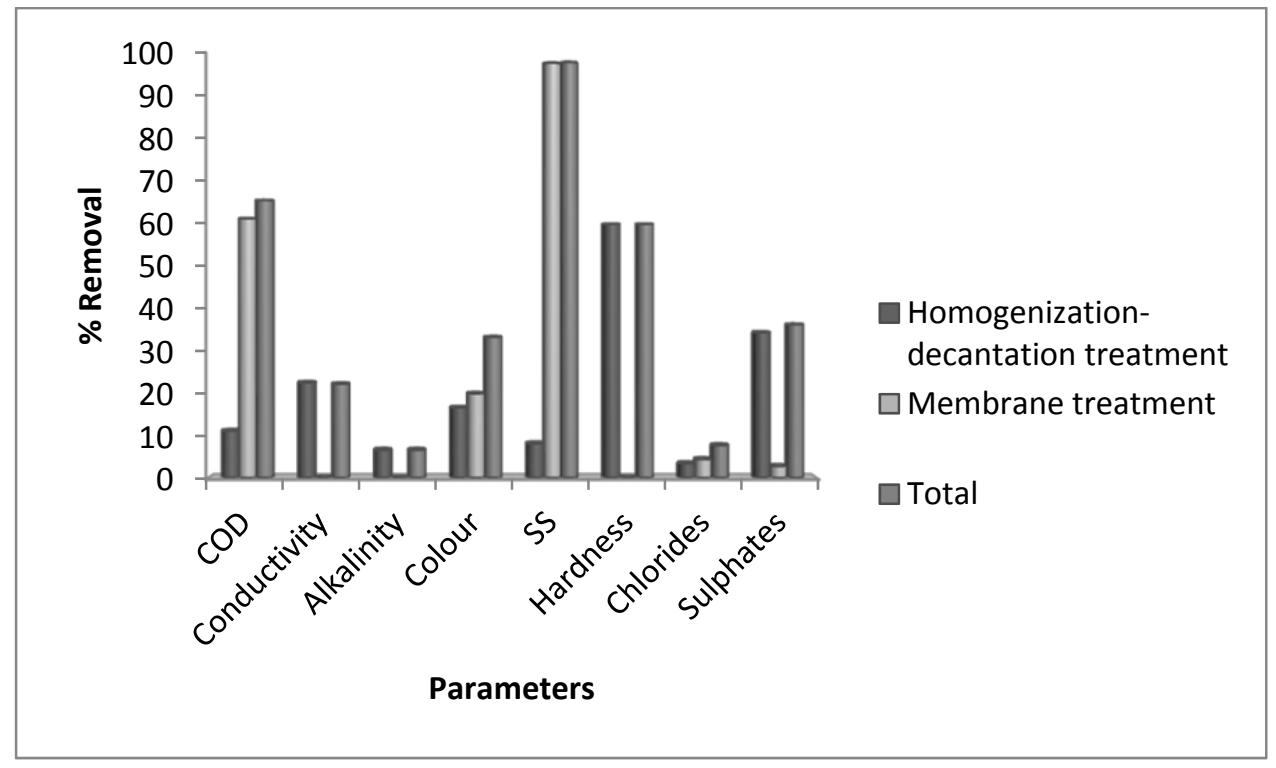

Figure 6- \% Removal in the different treatments

At the end of both treatments, the COD removal was $66 \%$ and colour reduction was about $30 \%$. The highest efficiency was obtained with the suspended solids (98\%). The decrease in the conductivity was mainly due to the reduction of sulphate ions obtained in the homogenization-decantation treatment.

\subsubsection{Semi-industrial pilot}

On the basis of the promising results obtained at lab scale, the membrane behaviour was tested at semi-industrial scale during 2 days with the pilot 2 . The trans-membrane pressure was also set up at 0.2 bar. A constant permeate flux of $15 \mathrm{~L} \cdot \mathrm{m}^{-2} \cdot \mathrm{h}^{-1}$ was 
obtained. As in the case of pilot 1, membrane fouling was not observed at the working conditions.

During this study, two effluents (E4 and E5) were treated. The efficiency of the membrane process was also determined with the permeate characterization (P4 and P5). Their main characteristics and the efficiency of the process are shown in Table 4.

Table 4- Effluents characterization and efficiency in the membrane treatment with U-4 membrane

\begin{tabular}{ccccccc}
\hline Parameter & E4 & P4 & $\%$ & E5 & P5 & $\%$ \\
\hline $\mathrm{pH}$ & 7.4 & 7.7 & - & 7.4 & 7.8 & - \\
$\mathrm{COD}\left(\mathrm{mg} \cdot \mathrm{L}^{-1}\right)$ & 509 & 236 & 53.6 & 648 & 236 & 63.6 \\
Conductivity & 1521 & 1518 & 0.2 & 1557 & 1518 & 2.5 \\
$\left(\mu \mathrm{S} \cdot \mathrm{cm}^{-1}\right)$ & & & & & & \\
Alkalinity $\left({ }^{\circ} \mathrm{F}\right)$ & 17 & 16 & 5.9 & 17 & 16 & 5.9 \\
Colour $(\mathrm{mg} \mathrm{Pt}-$ & 300 & 150 & 50.0 & 300 & 250 & 16.7 \\
$\left.\mathrm{Co} \cdot \mathrm{L}^{-1}\right)$ & & & & & & \\
$\mathrm{SS}\left(\mathrm{mg} \cdot \mathrm{L}^{-1}\right)$ & 74 & 2 & 97.3 & 118 & 2 & 98.3 \\
${\mathrm{Hardness}\left({ }^{\circ} \mathrm{F}\right)}^{2}$ & 3 & 2 & 33.3 & 2 & 2 & - \\
$\mathrm{Cl}^{-}\left(\mathrm{mg} \cdot \mathrm{L}^{-1}\right)$ & 226 & 218 & 3.5 & 270 & 264 & 2.2 \\
$\mathrm{SO}_{4}{ }^{2-}\left(\mathrm{mg} \cdot \mathrm{L}^{-1}\right)$ & 240 & 229 & 4.6 & 268 & 253 & 5.6 \\
\hline
\end{tabular}

At the end of the process, $60 \%$ of COD removal was achieved. Colour removal obtained was $33 \%$, higher than with $U-1 b$ membrane. This was due to the pore size, which in this membrane is smaller. As in pilot 1 , the suspended solid were effectively removed. Regarding the ions, they passed through the membrane to the permeate. It can be noticed that the permeate characterization showed similar results than the lab pilot (section 3.2.1), which indicated that the treatment could be scaled to industrial scale. 


\subsection{Permeate reuse}

The treated effluents were used in order to study the feasibility of the permeate reuse. Monochromies were carried out with $100 \%$ of the permeate. Dyeings obtained were evaluated with respect to a reference dyeing (with softened tap water). Their colour differences $\left(\mathrm{DE}_{\mathrm{CMC}(2: 1)}\right)$ are shown in Table 5.

Table 5- Colour differences for monochromies

\begin{tabular}{|c|c|c|c|c|}
\hline Dye & DL & DC & $\mathrm{DH}$ & $\mathrm{DE}_{\mathrm{CMC}(2: 1)}$ \\
\hline \multirow{2}{*}{ FB } & 0.55 & -0.09 & -0.40 & 0.68 \\
\hline & 0.43 & -0.02 & -0.16 & 0.46 \\
\hline \multirow{2}{*}{ FS } & -0.15 & -0.11 & 0.38 & 0.42 \\
\hline & 0.00 & -0.24 & 0.26 & 0.35 \\
\hline \multirow{2}{*}{ FY } & -0.71 & -0.25 & -0.89 & 1.16 \\
\hline & -0.60 & -0.65 & -0.52 & 1.03 \\
\hline \multirow{2}{*}{ FR } & 0.13 & -0.27 & -0.59 & 0.66 \\
\hline & 0.07 & -0.20 & -0.52 & 0.56 \\
\hline \multirow{2}{*}{ FYB } & -0.35 & 0.23 & -0.49 & 0.65 \\
\hline & -0.36 & 0.23 & -0.49 & 0.65 \\
\hline \multirow{2}{*}{ FB150 } & 0.79 & -0.96 & -1.76 & 2.15 \\
\hline & 1.22 & -0.83 & -1.86 & 2.37 \\
\hline \multirow{2}{*}{ FM } & -1.10 & -0.19 & 0.92 & 1.45 \\
\hline & -0.89 & -0.12 & 0.78 & 1.19 \\
\hline \multirow{2}{*}{ FBL } & 0.24 & -0.34 & -0.31 & 0.52 \\
\hline & -0.02 & -0.48 & -0.39 & 0.62 \\
\hline \multirow{2}{*}{ FRU } & -0.65 & -0.22 & -0.15 & 0.70 \\
\hline & -0.51 & -0.28 & 0.03 & 0.58 \\
\hline
\end{tabular}


As can be seen, all $D E_{C M C(2: 1)}$ except the FB150 dye were lower than 1.5, which is the maximum value accepted by the quality control of mill. It is important to highlight that FB150 is an anthraquinone dye, with a compact aromatic ring structure, which may interact with the residual compounds of the permeate. $F Y$ and $F M$ showed $\mathrm{DE}_{\mathrm{CMC}(2: 1)}$ close to 1.5 , mainly due to $\mathrm{DL}$ and $\mathrm{DH}$ values.

The reuse of the permeate in dyeing processes with trichromies was also studied. The trichromies were made with three of the following dyes: FR, FY, FRU, FYB and FB150. Taking into account the results of FB150 in monochromies, the trichromies dyeings were performed with $50 \%$ permeate and $50 \%$ clean water. Dyeings were found to be acceptable, as in all cases $\mathrm{DE}_{\mathrm{CMC}(2: 1)}$ were clearly lower than 1.5 (Table 6). In this sense, further studies could be done to establish the maximum percentage of permeate that can be reused and fulfil the acceptance criteria.

Table 6- Colour differences for trichromies

\begin{tabular}{|c|c|c|c|c|}
\hline Colour Dyed & $\mathrm{DL}$ & $\mathrm{DC}$ & $\mathrm{DH}$ & $\mathrm{DE}_{\mathrm{CMC}(2: 1)}$ \\
\hline \multirow{2}{*}{ Purple } & -0.41 & -0.57 & 0.08 & 0.71 \\
& 0.37 & 0.60 & -0.07 & 0.70 \\
\hline \multirow{2}{*}{ Beige } & -0.14 & -0.30 & -0.70 & 0.78 \\
& 0.08 & -0.07 & -0.81 & 0.82 \\
\hline \multirow{2}{*}{ Red } & -0.38 & -0.63 & 0.04 & 0.74 \\
& 0.00 & -0.85 & 0.07 & 0.85 \\
\hline \multirow{2}{*}{ Blue-gray } & -0.50 & 0.15 & 0.49 & 0.71 \\
& -0.20 & -0.30 & 0.36 & 0.51 \\
\hline \multirow{2}{*}{ Light gray } & -0.13 & -0.23 & -0.70 & 0.75 \\
& -0.26 & -0.32 & -0.46 & 0.62 \\
\hline
\end{tabular}

The high water consumption in the industry and their scarcity in certain regions have caused the increase of water cost. In addition, the new environmental policies are 
focused on water recycling and reuse. Wastewater reuse involves both environmental and economic benefits. On the one hand it decreases the discharged of pollutant into the environment and on the other hand it allows to reduce water consumption and cost of depuration processes.

According to the company selected for this study, more than $5 \mathrm{~m}^{3}$ are required to produce $160 \mathrm{~m}$ of fabric. The price of municipal water is $2.64 € / \mathrm{m}^{3}$ (including wastewater discharge cost). Therefore, the permeate reuse can save up to $13 €$ per $160 \mathrm{~m}$ of fabric produced.

\section{Conclusions}

Textile effluents were treated by means of homogenization-decantation and membrane treatments.

The combination of two treatments provided almost $66 \%$ and $30 \%$ of COD and colour removal respectively. The membrane treatment was shown to be scalable at semiindustrial scale and no fouling was observed during the experiments.

Finally, it can be stated that results of the permeate reuse are promising for the textile industry. When $100 \%$ permeate was reused, the colour differences for monochromies were into the acceptance range, except for the FB150 dye. With 50\% permeate reuse, all trichromies fulfil the quality criteria. As the textile industry consumes large amounts of water, the homogenization-decantation followed by membrane treatment is an advantageous combination from both the environmental and economical points of view.

\section{Acknowledgments}

The authors thank financial support from the Spanish Ministry of Economy and Competitiveness (CTM2012-31461) and Valentina Buscio is granted by UPC. The authors are also grateful to Ana García and the staff of Vincolor S.A. for its collaboration in this work. 
References

[1] T. Chidambaram, Y. Oren, M. Noel, Fouling of nanofiltration membranes by dyes during brine recovery from textile dye bath wastewater, Chem. Eng. J. 262 (2015) 156-168.

[2] Y. Zheng, S. Yu, S. Shuai, Q. Zhou, Q. Cheng, M. Liu, et al., Color removal and COD reduction of biologically treated textile effluent through submerged filtration using hollow fiber nanofiltration membrane, Desalination. 314 (2013) 89-95.

[3] M. Liu, Z. Lü, Z. Chen, S. Yu, C. Gao, Comparison of reverse osmosis and nanofiltration membranes in the treatment of biologically treated textile effluent for water reuse, Desalination. 281 (2011) 372-378.

[4] Bes-Piá, M.I. Iborra-Clar, A. Iborra-Clar, J. a. Mendoza-Roca, B. Cuartas-Uribe, M.I. Alcaina-Miranda, Nanofiltration of textile industry wastewater using a physicochemical process as a pre-treatment, Desalination. 178 (2005) 343-349.

[5] T. Robinson, G. McMullan, R. Marchant, P. Nigam, Remediation of dyes in textile effluent: a critical review on current treatment technologies with a proposed alternative., Bioresour. Technol. 77 (2001) 247-55.

[6] U.Y. Nigmet Uzal, Levent Yilmaz, Nanofiltration and Reverse Osmosis for Reuse of Indigo Dye Rinsing Waters, Sep. Sci. Technol. 45 (2010) 331-338.

[7] M. Sala, M.C. Gutiérrez-Bouzán, Electrochemical Techniques in Textile Processes and Wastewater Treatment, Int. J. Photoenergy. 2012 (2012) 1-12.

[8] S. Barredo-Damas, M.I. Alcaina-Miranda, a. Bes-Piá, M.I. Iborra-Clar, a. IborraClar, J. a. Mendoza-Roca, Ceramic membrane behavior in textile wastewater ultrafiltration, Desalination. 250 (2010) 623-628.

[9] J. Blanco, F. Torrades, M. Morón, M. Brouta-Agnésa, J. García-Montaño, PhotoFenton and sequencing batch reactor coupled to photo-Fenton processes for textile wastewater reclamation: Feasibility of reuse in dyeing processes, Chem. Eng. J. (2013).

[10] M.A. Barakat, Adsorption and photodegradation of Procion yellow H-EXL dye in textile wastewater over TiO2 suspension, J. Hydro-Environment Res. 5 (2011) 137-142.

[11] M. Sala, M.C. Gutiérrez-Bouzán, Electrochemical treatment of industrial wastewater and effluent reuse at laboratory and semi-industrial scale, J. Clean. Prod. 65 (2014) 458-464.

[12] A. Aouni, C. Fersi, B. Cuartas-Uribe, A. Bes-Pía, M.I. Alcaina-Miranda, M. Dhahbi, Reactive dyes rejection and textile effluent treatment study using ultrafiltration and nanofiltration processes, Desalination. 297 (2012) 87-96.

[13] M.I. Alcaina-Miranda, C. García-Figueruelo, J.A. Mendoza-Roca, A. Bes-Piá, M.I. Iborra-Clar, A. Iborra-Clar, et al., Comparison of three NF membranes for the reuse of secondary textile effluents, Desalination. 241 (2009) 1-7. 
[14] Y.K. Ong, F.Y. Li, S.-P. Sun, B.-W. Zhao, C.-Z. Liang, T.-S. Chung, Nanofiltration hollow fiber membranes for textile wastewater treatment: Labscale and pilot-scale studies, Chem. Eng. Sci. 114 (2014) 51-57.

[15] E. Kurt, D.Y. Koseoglu-Imer, N. Dizge, S. Chellam, I. Koyuncu, Pilot-scale evaluation of nanofiltration and reverse osmosis for process reuse of segregated textile dyewash wastewater, Desalination. 302 (2012) 24-32.

[16] V. Buscio, M. Crespi, C. Gutiérrez-Bouzán, Sustainable Dyeing of Denim Using Indigo Dye Recovered with PVDF Ultrafiltration Membranes, J. Clean. Prod. (10.1016/j.jclepro.2014.12.016).

[17] E. Ellouze, N. Tahri, R. Ben Amar, Enhancement of textile wastewater treatment process using Nanofiltration, Desalination. 286 (2012) 16-23.

[18] A. Bes-Piá, B. Cuartas-Uribe, J.-A. Mendoza-Roca, M.I. Alcaina-Miranda, Study of the behaviour of different NF membranes for the reclamation of a secondary textile effluent in rinsing processes., J. Hazard. Mater. 178 (2010) 341-8.

[19] A. Bes-Piá, J.. Mendoza-Roca, M.I. Alcaina-Miranda, A. Iborra-Clar, M.I. IborraClar, Reuse of wastewater of the textile industry after its treatment with a combination of physico-chemical treatment and membrane technologies, Desalination. 149 (2002) 169-174.

[20] M. Riera-Torres, C. Gutiérrez-Bouzán, M. Crespi, Combination of coagulationflocculation and nanofiltration techniques for dye removal and water reuse in textile effluents, Desalination. 252 (2010) 53-59.

[21] F. Harrelkas, A. Azizi, A. Yaacoubi, A. Benhammou, M.N. Pons, Treatment of textile dye effluents using coagulation-flocculation coupled with membrane processes or adsorption on powdered activated carbon, Desalination. 235 (2009) 330-339.

[22] B.-B. Lee, K.-H. Choo, D. Chang, S.-J. Choi, Optimizing the coagulant dose to control membrane fouling in combined coagulation/ultrafiltration systems for textile wastewater reclamation, Chem. Eng. J. 155 (2009) 101-107.

[23] D. De Jager, M.S. Sheldon, W. Edwards, Colour removal from textile wastewater using a pilot-scale dual-stage MBR and subsequent RO system, Sep. Purif. Technol. 135 (2014) 135-144.

[24] S.M. Burkinshaw, G. Salihu, The wash-off of dyeings using interstitial water. Part 4: Disperse and reactive dyes on polyester/cotton fabric, Dye. Pigment. 99 (2013) 548-560.

[25] Standard Methods for the Examination of Water and Wastewater, 22th ed., 2012 American Public Health Association/American Water Works Association/Water Environment Federation, Washington, DC.

[26] AENOR. UNE-EN ISO105-J03, 2009. Test for colour fastness. Part J03: Calculation of Colour Differences. Spanish Association for the Standardization and Certification, Madrid, Spain (in Spanish). 
[27] P. Wang, Z. Wang, Z. Wu, S. Mai, Fouling behaviours of two membranes in a submerged membrane bioreactor for municipal wastewater treatment, J. Memb. Sci. 382 (2011) 60-69.

[28] F. Meng, S.-R. Chae, A. Drews, M. Kraume, H.-S. Shin, F. Yang, Recent advances in membrane bioreactors (MBRs): membrane fouling and membrane material., Water Res. 43 (2009) 1489-512.

[29] S.J. Oh, N. Kim, Y.T. Lee, Preparation and characterization of PVDF/TiO2 organic-inorganic composite membranes for fouling resistance improvement, J. Memb. Sci. 345 (2009) 13-20.

[30] S. Zhang, R. Wang, S. Zhang, G. Li, Y. Zhang, Treatment of wastewater containing oil using phosphorylated silica nanotubes (PSNTs)/polyvinylidene fluoride (PVDF) composite membrane, Desalination. 332 (2014) 109-116.

[31] X. Shi, G. Tal, N.P. Hankins, V. Gitis, Fouling and cleaning of ultrafiltration membranes: A review, J. Water Process Eng. 1 (2014) 121-138.

[32] J. Dasgupta, J. Sikder, S. Chakraborty, S. Curcio, E. Drioli, Remediation of textile effluents by membrane based treatment techniques: A state of the art review., J. Environ. Manage. 147 (2015) 55-72. 